Relations industrielles

Industrial Relations

\title{
Les comités d'entreprise en France
}

\section{Jean-Pierre Després}

Volume 1, numéro 3, novembre 1945

URI : https://id.erudit.org/iderudit/1023908ar

DOI : https://doi.org/10.7202/1023908ar

Aller au sommaire du numéro

Éditeur(s)

Département des relations industrielles de l'Université Laval

ISSN

0034-379X (imprimé)

1703-8138 (numérique)

Découvrir la revue

Citer cet article

Després, J.-P. (1945). Les comités d'entreprise en France. Relations industrielles / Industrial Relations, 1(3), 3-3. https://doi.org/10.7202/1023908ar

Tous droits réservés @ C Département des relations industrielles de l’Université Laval, 1945
Ce document est protégé par la loi sur le droit d'auteur. L’utilisation des services d'Érudit (y compris la reproduction) est assujettie à sa politique d'utilisation que vous pouvez consulter en ligne.

https://apropos.erudit.org/fr/usagers/politique-dutilisation/ 


\section{LES COMITÉS D'ENTREPRISE EN FRANCE}

Parmi les aspirations légitimes (1) de la classe ouvrière, la participation à l'administration des entreprises présente un intérêt particulier. Aujourd'hui, les ouvriers réclament non seulement des salaires et des conditions de travail convenables, mais ils désirent jouer un rôle à l'intérieur de l'entreprise, bref, participer à sa gestion. C'est un problème d'actualité qu'il importe d'envisager objectivement.

La participation peut revêtir trois formes : a) de conseil ; b) de contrôle ; c) de cogestion. Les deux premières modalités ne portent pas atteinte aux prérogatives essentielles du Capital ou du chef d'entreprise, alors que la troisième place sur le même pied travailleurs et actionnaires.

$A$. - Au Canada, de même qu'en Grande-Bretagne et aux Etats-Unis, la participation sous forme de conseil a donné des résultats tangibles; particulièrement dans les industries de guerre. En effet, les comités mixtès de production ont associé étroitement les travailleurs à la solution des problèmes techniques de la production. Sans empiéter sur le.domaine propre des syndicats, ces comités ont comblé une lacune qui existait auparavant dans les relations industrielles.

B. - En France, le Gouvernement provisoire a adopté, en février 1945, une ordonnance instituant des comités d'entreprise. Accédant à une ancienne revendication syndicale, le ministre du Travail a institué $l a$ participation sous forme de contrôle, évitant ainsi la participation sous forme de cogestion réclamée en certains milieux. Les comités d'entreprise français ont un champ d'action plus vaste et un rôle plus étendu que nos comités mixtes de production. Ils doivent assurer, au sein des entreprises, une collaboration efficace entre les différents éléments concourant à la production : chefs d'entreprises, techniciens et salariés. Les syndicats désignent les candidats qu'ils désirent voir siéger sur les comités ; ces candidats ont ensuite toute liberté d'agir indépendamment des directives des syndicats. Les comités d'entreprise exercent leurs fonctions sur le plan social et le plan économique.

$1^{\circ}$ Sur le plan social, les comités ont pour mission d'améliorer les conditions de travail, excepté les salaires qui relèvent de l'action syndicale propre. De plus, ils assurent l'administration de toutes les ouvres sociales établies dans les entreprises au bénéfice des salariés ou de leurs familles.

$2^{\circ}$ Sur le plan économique, les comités d'entreprise ne jouent qu'un rôle consultatif et ils n'ont qu'un droit de regard. A titre consultatif, les comités ont les attributions suivantes : a) ils étudient toutes les suggestions émises par le personnel en vue d'accroître la production et d'améliorer le rendement des entreprises et proposent l'application de celles qu'ils jugent opportunes : b) ils

(1) Nous estimons, cependant, plus approprié aux conditions présentes de la vie sociale, de tempérer quelque peu, dans la mesure du possible, le contrat de travail par des éléments empruntés au contrat de société. C'est ce que l'on a déjà commencé à faire, sous des formes variées, non sans profit sensible pour les travailleurs et pour les possesseurs du capital. Ainsi, les ouvriers et les employés ont été appelés à participer en quelque manière à la propriété de l'entreprise, a sa gestion ou aux profits qu'elle apporte ». Quadragesimo Anno. proposent en faveur des travailleurs ayant apporté par leur initiative ou leurs propositions une collaboration particulièrement utile à l'entreprise, toute récompense qui leur semble méritée; c) ils sont obligatoirement injormés des questions intéressant l'organisation, la gestion et la marche générale de l'entreprise. Les chefs d'entreprises doivent faire, au moins une fois par an, un exposé de la situation et des activités de leur organisation et soumettre leurs projets pour l'exercice suivant. De plus, lorsque l'entreprise est constituée sous la forme d'une société par action ou qu'elle réunit d'une façon continue, quelle que soit sa forme, plus de cinq cents salariés, le comité est, en outre, informé des bénéfices réalisés et peut émettre des suggestions sur leur emploi. Enfin, dans les entreprises qui revêtent la forme d'une société anonyme, la direction est tenue de communiquer au comité, avant de les présenter à l'assemblée générale des actionnaires, le compte de profits et pertes, le bilan annuel et le rapport des commissaires aux comptes ainsi que les autres documents qui seraient soumis à telle assemblée générale. Voilà, en résumé, les principales dispositions de l'ordonnance de février 1945.

C. - La participation sous forme de cogestion est évidemment plus complète. En pareil cas, les représentants des travailleurs sont sur un pied d'égalité avec les représentants des actionnaires. Les comités de cogestion sont dotés d'un pouvoir de décision et de commandement, alors que les comités d'entreprise n'ont qu'un rôle consultatif et un droit de regard.

Ce bref exposé suffit à démontrer les différences qui existent entre nos comités mixtes de production et les comités d'entreprise. Alors que ceux-ci ont un caractère général, permanent et obligatoire, ceux-là sont volontaires. Non seulement les comités d'entreprise ont des pouvoirs beaucoup plus étendus, mais les employeurs ne peuvent s'opposer à leur formation. Cette formule est un compromis entre la cogestion intégrale de l'entreprise et la simple participation à la gestion sous forme de conseil. Sur le plan social, les travailleurs ont un pouvoir d'administration alors que sur le plan économique, leur rôle n'est que consultatif.

Néanmoins, l'ordonnance française représente une réforme audacieuse que plusieurs considèrent comme un stage préalable imposé aux travailleurs avant de les admettre à siéger de plein droit dans les conseils d'administration. Toutes les organisations syndicales ont donné le mot d'ordre suivant : "Aux travailleurs de faire un succès des comités d'entreprise et ils pourront alors aspirer à la cogestion économique ". Un analyste objectif écrivait récemment : " L'ordonnance du 22 février 1945, en résumé, a sagement tenu compte des expériences étrangères. Elle a créé une institution compatible avec le régime capitaliste des entreprises actuelles et donc, a réformé celles-ci sans les bouleverser. Elle contient des dispositions qui assurent le maintien de l'autorité des chefs et d'autres garantissant que les rapports seront pacifiques entre les comités et les organisations syndicales "). Telle semble être l'opinion courante en France. 